\title{
Recurrent Psychosis after Phentermine Administration in a Young Female: A Case Report
}

\author{
Hyun-Sic Jo ${ }^{1}$, Sheng-Min Wang ${ }^{1,2}$, Jung Jin Kim ${ }^{1}$ \\ ${ }^{1}$ Department of Psychiatry and ${ }^{2}$ International Health Care Center, Seoul St. Mary's Hospital, College of Medicine, The Catholic University of \\ Korea, Seoul, Korea
}

\begin{abstract}
Phentermine is a sympathomimetic amine, like amphetamine, which is one of the most often prescribed drugs for weight loss. Although exact mechanism of phentermine causing psychosis is still not clear, numerous reports already showed that phentermine can induce psychosis. Psychotic symptoms are generally resolved once the medications are stopped. In contrast, we present a case of a 25-years-old Asian female patient who developed psychotic symptoms repeatedly after phentermine administrations. This case suggests that phentermine can cause psychotic episodes repeatedly, resulting in chronic occupational and social impairment. Therefore, a precautious measure such as government regulations for physicians prescribing and an education for patients taking phentermine are urgently needed.
\end{abstract}

KEY WORDS: Phentermine; Adverse reaction; Psychotic disorders; Recurrence.

\section{INTRODUCTION}

2014 Korean National Health Survey showed that $31.5 \%$ of Koreans over 19 years old are obese defined by World Health Organization Western Pacific Regional Office criteria (obese: body mass index [BMI] higher than $25 \mathrm{~kg} / \mathrm{m}^{2}$ ). The obesity rate of general population in Korea was $26.0 \%$ in 1998 , which has risen to $31-33 \%$ since 2007. ${ }^{1)}$ Diet modification, exercise, and life style change are recommended as the first-line treatments of obesity. ${ }^{2)}$ However, effects of lifestyle intervention are not always satisfactory, so several medications were tried and thus approved by the United States Food and Drug Administration (FDA) for obesity. Pharmacotherapy is indicated in individuals with a BMI of $\geq 25 \mathrm{~kg} / \mathrm{m}^{2}$, or those with a BMI of $\geq 23 \mathrm{~kg} / \mathrm{m}^{2}$ and having comorbidities such as hypertension, dyslipidemia, type 2 diabetes mellitus, or sleep apnea. ${ }^{3)}$ Korea is world known for being an

Received: March 6, 2017 / Revised: May 12, 2017

Accepted: May 14, 2017

Address for correspondence: Jung Jin Kim, MD, PhD

Department of Psychiatry, Seoul St. Mary's Hospital, College

of Medicine, The Catholic University of Korea, 222

Banpo-daero, Seocho-gu, Seoul 06591, Korea

Tel: +82-2-2258-6084, Fax: +82-2-2258-6084

E-mail: jjean@catholic.ac.kr

ORCID: https://orcid.org/0000-0003-3899-5579 "appearance-obsessed" country, so many young females use or sometimes abuse "diet pills" to lose their weight. In terms of using diet pills and appetite suppressants, Korea ranks near the top of the globe. A research showed that up to $13 \%$ of female aged 15 to 59 years used or were using diet pills. ${ }^{4)}$ FDA-approved anti-obesity drugs are orilistat, lorcaserin, phentermine/topiramate, naltrexone/bupropion and liraglutide. ${ }^{5)}$

Phentermine, which was approved in 1959 for weight loss, remains the most often prescribed drug for weight loss in the United States. ${ }^{6}$ ) Phentermine was approved for short-terms uses only, which is widely interpreted as up to 12 weeks, and its usual dose is $37.5 \mathrm{mg} /$ day. ${ }^{2,6)}$ It is sympathomimetic amines, like amphetamine, which is nonselective stimulator of synaptic noradrenaline, dopamine, and serotonin release. However, unlike amphetamine, it has very little effect on dopamine release at the neuronal synapse. ${ }^{5,7)}$ The introduction of phentermine to Korea was much later than that of the United States. However, it has become the most widely used diet pills since its approval in 2004. ${ }^{5,8)}$ According to a report by the Ministry of Food and Drug Safety, production performance of phentermine in Korea was 19,795 million Korean won (KRW; about 17 million dollars) in 2010, 43,553 million KRW (about 38 million dollars) in 2014, and 38,878 million KRW (about

(c) This is an Open-Access article distributed under the terms of the Creative Commons Attribution Non-Commercial License (http://creativecommons.org/licenses/by-nc/4.0) which permits unrestricted non-commercial use, distribution, and reproduction in any medium, provided the original work is properly cited. 
34 million dollars) in 2015. ${ }^{9}$

Like many other sympathomimetics, phentermine is known to induce psychotic symptoms. Thus, phentermine associated psychotic symptoms have been reported repeatedly since 1960 s. $^{10)}$ Once the medications are stopped, psychotic symptoms generally improve in patients who had no prior history of psychotic disorder. Here we report a 25 years old woman whose psychotic symptoms recurred multiple times after re-administration of phentermine.

\section{CASE}

A 25-year-old Korean female patient was admitted to an acute psychiatric ward in April 2016 due to psychotic symptoms. A detailed mental status examination showed persecutory delusion, delusion of reference and auditory hallucination which occurred 6 weeks before admission. History revealed that she became pre-occupied with her body image from time to time. Thus, she has been taking diet pills and have presented with psychotic symptoms multiple times in the past. She first started taking diet pills in April 2011 from a medical clinic nearby. The medications included Furimin tablet ${ }^{\circledR}$ (phentermine 37.5 mg; Alvogen Korea, Seoul, Korea), L-Carina tablet ${ }^{\circledR}$ (330 mg; Alvogen Korea), Aeiol tablet ${ }^{\circledR}$ (alginic acid 200 mg, carboxymethyl-cellulose 100 mg; Pharvis Korea, Seoul, Korea), Therrmofen-S tablet ${ }^{\circledR}$ (acetaminophen 200 mg, caffeine $40 \mathrm{mg}$, ephedrine $15 \mathrm{mg}$; Alvogen Korea). She first took these medications irregularly and often developed idea of reference. She often avoided social interaction, such as refusing to participate in a group project at her college classes, but these symptoms did not cause significant problems.

She started to overdose phentermine (112.5-150.0 mg/day) from November 2012, which was immediately after she broke up with her boyfriend. Three to four weeks later, she displayed psychotic symptoms including persecutory delusion and delusion of reference, so she was not able to attend school and had to take a year of sick leave from her college. She was recommended to take antipsychotics by a psychiatrist in a primary neuropsychiatric clinic, but she refused to do so. Thereafter, she stopped taking phentermine, and her psychotic symptoms subsided 3 weeks after phentermine cessation.

After returning to her school in February 2014, she be- came pre-occupied with her body image once again. As a result, she started re-taking phentermine irregularly and showed idea of reference from time to time. Her use of phentermine became regular from early 2015 which progressed to taking four times its recommended dosage of $150 \mathrm{mg} /$ day from 2 months before admission. Shortly after, she started to feel that her coworkers were constantly watching her and trying to physically abuse her. She also started having auditory hallucinations; voices of her parents criticizing her about taking phentermine. She also became violent and threat to her own safety. Thus, she was hospitalized to our psychiatric ward by her legal guardian.

On admission, her affect was slightly tense, and she complained of delusion of reference, persecutory delusion, and inappropriate guilt. Her BMl was $23 \mathrm{~kg} / \mathrm{m}^{2}$ (height, $163 \mathrm{~cm}$; weight, $61 \mathrm{~kg}$ ), and she was preoccupied with her body weight. Initial Positive and Negative Syndrome Scale (PANSS) score was 95. She had no previous neuropsychiatric history, history of physical illness, and family history of psychiatric illness. She did not have any suicidal ideation or attempt. Results of routine laboratory tests were normal. She was tested positive only for ephedrine on the urine drug screening.

We diagnosed her with substance-induced psychotic disorder because she never experienced psychotic symptoms before she took the diet pills. Among diet pills she had taken, ephedrine and caffeine may also induce psychosis. However, very few cases report ephedrine or caffeine induced psychosis episodes. In addition, the dosage of ephedrine and caffeine that she took was very low to induced psychosis. ${ }^{11,12)}$ In contrast, it is well known that overdose or continuous use of phentermine can cause psychotic symptoms. ${ }^{13)}$ Therefore, we concluded that phentermine was the most likely cause of her psychotic symptoms.

We prescribed her antipsychotic because her psychotic symptoms persisted although she had stopped taking the diet pills from 3 days before admission. We chose aripiprazole because it has less risk of causing weight gain. ${ }^{14,15)}$ Additionally, we prescribed her lorazepam and benztropine. We increased aripiprazole to $15 \mathrm{mg}$ on the 4th day of admission. After the 8th day of admission, her delusion subsided substantially, and she interacted appropriately within the psychiatric ward. Moreover, she started having insight about her symptoms and realized the risk of over- 
dosing phentermine. Her symptoms improved gradually, and she was discharged on the 28th day of admission. On discharge, her PANSS score was dramatically improved to 20. She has been following up at our outpatient clinic without relapse of any psychotic symptom.

\section{DISCUSSION}

Phentermine has been known as an effective appetite suppressant with weight reduction effect. ${ }^{16,17)}$ Phentermine is a substrate-type releaser at norepinephrine and dopamine transporters, with less potent effects at serotonin in the brain. ${ }^{18)}$ These actions of phentermine may contribute to anti-appetite effect. Although side effects of phentermine have been generally tolerable ${ }^{8)}$ it can cause tachycardia, hypertension, visual symptoms, nausea, insomnia and anxiety. ${ }^{19)}$ Moreover, phentermine may be associated with affective symptoms including manic-like episode. ${ }^{20)}$

Our case showed that patients may experience repeated psychotic episodes with phentermine administration. To the best of our knowledge, there was only one previous case report which showed recurrence of psychotic symptoms after phentermine administration. ${ }^{21)}$ In our case, she stared experiencing mild psychotic symptoms when she first took phentermine intermittently, and the psychotic symptoms resolved without any treatment after she stopped taking it. Psychotic symptoms relapsed and aggravated when she started re-taking phentermine, more frequently and excessively.

Although exact mechanism of phentermine causing psychosis is still not clear, numerous reports already showed phentermine induced psychosis. ${ }^{13,21-25)}$ A number of amphetamine related drugs including phentermine are known as antiobesity drugs and they are structurally related to amphetamine. ${ }^{20)}$ It is known that phentermine does not release dopamine at a clinically significant quantity compared with amphetamine, ${ }^{5)}$ but it is not possible to conclude that phentermine has no effect on dopamine. ${ }^{18)}$ Likewise, a previous report emphasized that phentermine could elevate dopamine. ${ }^{13)}$ Most cases associated with amphetamine analogues like phentermine did not show associative loosening or social withdrawal symptoms. ${ }^{13)}$ In addiction, the report suggested the difference between psychosis induced by amphetamine analogues and schizophrenia is the absence of marked negative symptoms. ${ }^{13)}$
Main positive symptoms of phentermine induced psychosis included persecutory delusion and auditory hallucination. Like previous report, our case did not show any significant negative symptoms but showed overt positive symptoms including persecutory delusion and auditory hallucination.

No studies have yet investigated longer-term psychosis related to phentermine although these symptoms can appear repeatedly and cause significant social impairment especially in young adults. Therefore, researches about chronicity or repetition of phentermine induced psychosis are needed in the near future. In addition, understanding who has a higher risk of developing psychotic symptoms could prevent physicians from letting these high-risk people to take phentermine. Thus, future studies should also focus on investigating individuals' susceptibility of developing overt psychosis with phentermine administration. More importantly, the government has implemented a strict regulation to prevent patients from overdosing hypnotics, such as zolpidem and triazolam. ${ }^{26)}$ The Korean government is also concerned about benzodiazepine abuse, but no regulation is implemented for phentermine despite the fact that it can cause severe psychopathologies (psychotic symptoms). This study suggests that, just like black box warning of selective serotonin reuptake inhibitor for suicide, there should be a precautious measure for physicians who plan to give phentermine to patients. Before prescribing phentermine, physicians should investigate patient's history of psychiatric illness including psychotic disorder. In addition, precautious measurements are needed so that physicians would not overlook patient's psychotic symptoms even if they are mild in severity. Moreover, patients who are prescribed phentermine need an education about psychiatric side effects.

\section{- Acknowledgments}

This study was supported by Research Fund of Seoul St. Mary's Hospital, The Catholic University of Korea (ZC16FISI0072). The authors have no conflict of interests.

\section{REFERENCES}

1. Ministry of Health and Welfare, Korea Centers for Disease Control and Prevention. Korea Health Statistics 2014: Korea National Health and Nutrition Examination Survey (KNHANES VI-2). Sejong:Korea Centers for Disease Control and Preven- 
tion;2015.

2. Korean Society for the Study of Obesity. Guideline for treatment of obesity 2012. Seoul:Korean Society for the Study of Obesity;2012.

3. Kim KK. Pharmacotherapy for obesity. J Korean Med Assoc 2011;54:409-418.

4. Chosunilbo. Koreans overdose on diet pills [Internet]. Seoul: Chosunilbo \& Chosun.com; 2010 Mar 27 [cited at 2017 Jan 20]. Availble form: http://eng/ish.chosun.com/site/data/htm/ dir/2010/03/27/2010032700362.htm/.

5. Daneschvar HL, Aronson MD, Smetana GW. FDA-approved anti-obesity drugs in the United States. Am J Med 2016;129: 879.e1-6.

6. Bray GA, Ryan DH. Update on obesity pharmacotherapy. Ann NYAcad Sci 2014;1311:1-13.

7. Bray GA. A concise review on the therapeutics of obesity. Nutrition 2000;16:953-960.

8. Kim KK, Cho HJ, Kang HC, Youn BB, Lee KR. Effects on weight reduction and safety of short-term phentermine administration in Korean obese people. Yonsei Med J 2006;47:614625.

9. Ministry of Food and Drug Safety. Explanation materials of Yonhap News's coverage [Internet]. Cheongju: Ministry of Food and Drug Safety; 2016 Aug 12 [cited at 2017 Apr 28]. Availble form: http://www.mfds.go.kr/index.do?mid=676\& seq $=32976 \&$ sitecode $=1 \& \mathrm{cmd}=\mathrm{v}$.

10. Rubin RT. Acute psychotic reaction following ingestion of phentermine. Am J Psychiatry 1964;120:1124-1125.

11. Shufman NE, Witztum E, Vass A. [Ephedrine psychosis]. Harefuah 1994;127:166-168, 215. Hebrew.

12. Wang HR, Woo YS, Bahk WM. Caffeine-induced psychiatric manifestations: a review. Int Clin Psychopharmacol 2015;30: 179-182.

13. Kwon SJ, Yang JC, Park TW, Chung YC. Appetite suppressor induced psychosis. Clin Psychopharmacol Neurosci 2010;8: 170-174.

14. Hatano M, Kamei H, Kato A, Takeuchi I, Hanya M, Uno J, et al. Assessment of the latent adverse events of antipsychotic treatment using a subjective questionnaire in Japanese patients with schizophrenia. Clin Psychopharmacol Neurosci 2017;15:132-137.

15. Briegel W. Clinical usefulness of aripiprazole treatment in a girl with Prader-Willi syndrome and psychosis. Clin Psychopharmacol Neurosci 2018;16:497-500.

16. Munro JF, MacCuish AC, Wilson EM, Duncan LJ. Comparison of continuous and intermittent anorectic therapy in obesity. $\mathrm{Br}$ Med 1 1968;1:352-354.

17. Langlois KJ, Forbes JA, Bell GW, Grant GF Jr. A double-blind clinical evaluation of the safety and efficacy of phentermine hydrochloride (Fastin) in the treatment of exogenous obesity. Curr Ther Res Clin Exp 1974;16:289-296.

18. Rothman RB, Baumann MH. Neurochemical mechanisms of phentermine and fenfluramine: therapeutic and adverse effects. Drug Dev Res 2000;51:52-65.

19. Ku JE, Joo YS, You JS, Chung SP, Lee HS. Two cases of intoxication with phentermine. J Korean Soc Clin Toxicol 2014; 12:35-38.

20. An H, Sohn H, Chung S. Phentermine, sibutramine and affective disorders. Clin Psychopharmacol Neurosci 2013;11:712.

21. Devan GS. Phentermine and psychosis. Br J Psychiatry 1990;156:442-443.

22. Alexander J, Cheng YH, Choudhary J, Dinesh A. Phentermine (Duromine) precipitated psychosis. Aust N Z J Psychiatry 2011;45:684-685.

23. Cleare AJ. Phentermine, psychosis, and family history. J Clin Psychopharmacol 1996;16:470-471.

24. Hoffman BF. Diet pill psychosis. Can Med Assoc J 1977;116: 351-355.

25. Lee SH, Liu CY, Yang YY. Schizophreniform-like psychotic disorder induced by phentermine: a case report. Zhonghua Yi Xue Za Zhi (Taipei) 1998;61:44-47.

26. National Law Information Ceter, Korea. [Enforcement rule of standard for medical care benefit of National Health Insurance, 2017]. Sejong:National Law Information Center;2017. Korean. 